\title{
What Derivations Cannot Do
}

I think that there is much about contemporary philosophy of religion that should change. Most importantly, philosophy of religion should be philosophy of religion, not merely philosophy of theism, or philosophy of Christianity, or philosophy of certain denominations of Christianity, or the like. Here, however, I shall complain about one fairly narrow aspect of contemporary philosophy of religion that really irks me: its obsession with derivations that have as their conclusion either the claim that God exists or the claim that God does not exist. I shall work myself up by degrees.

\section{1.}

Suppose that PRO and CON are disputing about CLAIM: PRO says that CLAIM is true; CON says that CLAIM is false. Suppose, further, that PRO believes all of $\mathrm{p}_{1}, \ldots, \mathrm{p}_{\mathrm{n}}, \ldots$, CLAIM $, \mathrm{q}_{1}, \ldots, \mathrm{q}_{\mathrm{m}}, \ldots$, and that CON believes all of $\mathrm{p}_{1}, \ldots, \mathrm{p}_{\mathrm{n}}, \ldots, \sim$ CLAIM $, \sim \mathrm{q}_{1}, \ldots, \sim \mathrm{q}_{\mathrm{m}}, \ldots$ If PRO presents a derivation to CON, with CLAIM as its conclusion, what conditions should this derivation satisfy if it is to constitute a worthwhile move in their disputation?

The derivations that PRO might offer to $\mathrm{CON}$ are of two kinds.

First, there are derivations in which the premises are all claims that $\mathrm{CON}$ accepts: claims from among the $p_{i}$ and the $\sim q_{j}$. A proper derivation of CLAIM from premises among the $p_{i}$ and the $\sim \mathrm{q}_{\mathrm{j}}$ can create a serious problem for CON: after all, on the one hand, he believes CLAIM; and, on the other hand, there is a derivation of CLAIM from other things that he believes. Unless the derivation is of a kind that only provides very weak support for conclusions given premises, the derivation gives $\mathrm{CON}$ reason to reconsider his beliefs.

Second, there are derivations in which one or more of the premises is a claim that PRO accepts and CON rejects: one or more of the premises is among the $\mathrm{q}_{\mathrm{j}}$. In this case, even if there is a proper derivation of CLAIM from these premises, the derivation creates no problem for CON. After all, PRO and CON both already know - from the fact that they disagree about CLAIM - that you can derive a contradiction if you put together claims that PRO believes with claims that CON believes. It is absurd to claim that the derivation of CLAIM from CLAIM constitutes a worthwhile move to make in disputation about CLAIM; it is no less absurd to claim that putting forward a derivation of CLAIM with one or more of the $\mathrm{q}_{\mathrm{j}}$ among its premises is a worthwhile move for PRO to make.

In the case of PRO and CON, then, the only kinds of derivations which have either CLAIM or CLAIM as their conclusion that constitute worthwhile contributions to their dispute about CLAIM are reductios: derivations which establish a conflict between beliefs-including either CLAIM or CLAIM - all of which are held by one of the parties to the dispute.

Of course, PRO and CON are highly idealised. In a more realistic case, there will be claims that one believes but concerning which the other withholds opinion; and there will be claims that one believes but which the other has not even considered; and there may even be claims that one believes but with respect to which the other does not even have the concepts required to formulate it. Moreover, in more realistic cases, disputants do not know exactly what their 
interlocutors believe (apart from claims that have been explicitly tabled as part of their dispute).

However, even in these more complicated cases, the basic lesson remains the same. The first step to take, prior to setting out a derivation with either CLAIM or CLAIM as its conclusion, is to establish that you opponent believes all of the premises that figure in the derivation that you are tempted to give. If you opponent fails to believe one or more of those premises, then there is no useful purpose that is served by your continuing on to give that derivation. True enough, if there are premises in your derivation that your opponent has not previously considered, then your giving the derivation might lead your opponent to consider and then accept those premises - and then, after accepting those premises, your derivation will establish that your opponent has some cognitive work to do. But, in the first instance, all that is required is that you present the premises in question to your opponent: giving the derivation is surplus to requirement if either (a) your opponent fails to accept the premises when they are presented, or (b) your opponent is able to discern the implication of acceptance of the premises without being presented with the derivation.

Any dispute between two people is a highly idiosyncratic matter: a derivation that would advance a dispute between two people may well have no wider significance. Moreover, the same is true for disputes between particular populations of people: these, too, might be lacking in any wider significance.

From the standpoint of philosophy, what we are really interested in are best theories that include claims of interest: CLAIM and CLAIM respectively. If we have a derivation that establishes, or even that merely appears to establish, that a best theory that includes CLAIM is - or, more strongly, that all best theories that include CLAIM are-subject to reductio, then we have a derivation with CLAIM as conclusion that is worthy of serious philosophical attention. Moreover, it is only if we have a derivation that establishes, or even that merely appears to establish, that a best theory that includes CLAIM is - or, more strongly, that all best theories that include $\sim$ CLAIM are - subject to reductio, then we have a derivation with $\sim$ CLAIM as conclusion that is worthy of serious philosophical attention.

Suppose that CLAIM is a claim about which there is widespread disagreement amongst philosophers. How might a derivation with either CLAIM or CLAIM as its conclusion make a contribution to this dispute? I suggest that we should think about this matter in the following terms.

At the outset, we should try as hard as we can to frame best theories that embed both CLAIM and CLAIM. In particular, we should try to produce best theories that are worked out to the same level of detail, that try to cover the same range of data, and so forth. Once we have our best theories $-\mathrm{T}_{\text {CLAIM }}$ and $\mathrm{T}_{\sim \mathrm{CLAIM}}$ - there is a two-stage assessment process.

First, we consider whether either theory can be defeated on internal grounds: that is, we consider whether either theory is vulnerable to reductio. This is where derivation with either 
CLAIM or CLAIM as conclusion comes in: a derivation of this kind can be used to show that a best theory is defeated on internal grounds.

Second, if our best theories survive internal scrutiny, then we turn to comparative assessment of the theoretical virtues of our best theories: which scores best on the proper weighting of simplicity, fit with data, explanatory scope, predictive accuracy, and so forth. In this part of theory assessment, there is evidently no proper role for derivation with either CLAIM or $\sim$ CLAIM as conclusion.

Of course, to say that there is no proper role for derivation with either CLAIM or CLAIM as conclusion in the second part of theory assessment is not to say that there is no proper role for derivation in the second part of theory assessment. In order to assess a theory, we need to know which claims are part of the theory; and any claim that is derivable from claims in a theory is part of that theory. But we already know that CLAIM and CLAIM are parts of the respective theories; we do not need to use derivations in order to establish this fact.

The point made in the last paragraph bears repeating. My claim is that, in the case of dispute about CLAIM, the only contribution that derivations with conclusion CLAIM or conclusion $\sim$ CLAIM can make to the resolution of the dispute lies in providing reductios of best theories that embed $\sim$ CLAIM or best theories that embed CLAIM. My claim is silent on the contributions that derivations with other conclusions might make to the resolution of this dispute; and my claim also says nothing about other contributions that derivations might make to the practice of philosophy.

Philosophers have claimed virtues for derivations with conclusion CLAIM or conclusion $\sim$ CLAIM even while acknowledging that their derivations do not provide reductios of best theories that embed $\sim$ CLAIM or best theories that embed CLAIM.

Some say that having such derivations may increase the worthiness of one's beliefs by increasing the confidence with which those beliefs are held; or by making one's beliefs more resilient and less liable to defeat; or by making one's system of beliefs more coherent; or by making one's system of beliefs a more reliable base from which to launch arguments against others; or by generating an increased understanding of one's system of beliefs. Some say that having such derivations provides insurance against dark days in which you come to have doubts about your beliefs. Some say that having such derivations can reveal interesting and important connections between one's beliefs. Some say that such derivations can be used to show to opponents that a particular position is a legitimate intellectual option.

Most of these claims are plainly mistaken. Suppose that your view is $\mathrm{T}_{\mathrm{CLAIM}}$ and your opponents view is $\mathrm{T}_{\sim \text { CLAIM. }}$ Suppose - for the sake of argument - that neither view is subject to internal defeat, but that $\mathrm{T}_{\sim \mathrm{CLAIM}}$ is much more theoretically virtuous than $\mathrm{T}_{\mathrm{CLAIM}}-\mathrm{i}$.e., $\mathrm{T}_{\sim \text { CLAIM }}$ scores much better than $\mathrm{T}_{\text {CLAIM }}$ on the proper weighting of simplicity, fit with data, explanatory scope, predictive accuracy, and so forth. In these circumstances, it would obviously be a mistake to suppose that having derivations of CLAIM from a bunch of claims 
that belong to $\mathrm{T}_{\text {CLAIM }}$ should increase the credence that you assign to $\mathrm{T}_{\text {CLAIM }}$ against the credence that you assign to $\mathrm{T}_{\sim \text { CLAIM }}$; or that this makes $\mathrm{T}_{\text {CLAIM }}$ more resilient and less liable to defeat by $\mathrm{T}_{\sim \text { CLAIM }}$; or that this somehow increases the coherence of one's beliefs in way that improves the standing of $\mathrm{T}_{\text {CLAIM }}$ relative to $\mathrm{T}_{\sim \text { CLAIM }}$; or that this makes $\mathrm{T}_{\text {CLAIM }}$ a more reliable base for launching arguments against $\mathrm{T}_{\sim \text { CLAIM }}$; or that this provides insurance against your recognising that you should abandon $\mathrm{T}_{\text {CLAIM }}$ in favour of $\mathrm{T}_{\sim \text { CLAIM }}$; or that this gives you ammunition to show to your opponents that the position that you have adopted is a legitimate intellectual option.

The remaining claims are plainly insignificant. Perhaps there could be some truth in the claim that having derivations of CLAIM from a bunch of claims that belong to $\mathrm{T}_{\text {CLAIM }}$ can generate an increased understanding of one's system of belief, and that it can reveal interesting and important connections between one's beliefs. But the understanding, interest, and importance at issue cannot have anything to do with reasons for preferring $\mathrm{T}_{\mathrm{CLAIM}}$ to competing theories such as $\mathrm{T}_{\sim \text { CLAIM }}$. I do not deny that there are interesting questions about, for example, the most economical axiomatisations of competing theories. However, I also think it obvious that we should not take this to be a crucially important focus of philosophical investigation.

\section{4}

Here is one standard format for a paper in philosophy of religion. (1) Provide some introductory remarks that form the background to the subsequent discussion. (2) State an argument - either with the conclusion that God exists, or the conclusion that God does not exist - in standard form. (3) Give a derivation which establishes that the conclusion of the argument is appropriately related to the premises. (4) Defend the premises of the argument, making more or less frequent appeal to the fact that the premises seem reasonable to the author. (5) Respond to objections, including, in particular, the charge that your argument is question-begging. (6) Conclude that your argument is a good or successful argument for its conclusion.

No paper that conforms to this format should ever see the light of day. This is not because we know for sure that there are both best theistic and best atheistic theories that survive internal defeat. I do think that we know that we are not currently in possession of reductios of best theistic and best atheistic theories; but, even if I am right about that, it is at the very least conceivable that we should one day be in possession of reductios of all best theistic theories or reductios of all best atheistic theories.

The real problem lies with (4) and (5). In order to "defend" the premises of your argument, what you need to do - and all that you need to do - is to establish that those premises are all parts of some particular best theory that entails - or perhaps even all best theories that entail - the falsity of the conclusion of the stated argument. Whether the premises are supported by the intuitions of the author is, of course, utterly irrelevant: if there are any intuitions that count, they belong to those who occupy the opposing position. Moreover, and for exactly the same reasons, there is no need to fuss about "begging the question": in giving 
a reductio, you are entitled to use any of the claims to which those against whom the reductio is directed are committed.

Although it is less important, it may also be worth noting that there can be a further problem with (6). Some papers that conform to this standard format claim to show that the conclusion is weakly supported by the premises: perhaps, for example, that the conclusion is slightly more probable, given the premises, than it would otherwise have been. However, even if nothing else has gone wrong with the paper, this is insufficient to establish anything that one might like to call a reductio: for it might well be that a claim in a theory is near certain given all the rest of the theory, but not at all probable given only some part of the theory.

\section{5}

Here is a standard format for an introductory course in philosophy of religion, or for a section on philosophy of religion in an introductory course in philosophy. (1) Give some brief account of the assessment of argument. (2) Give a brief account of theism: typically, a definition of God. (3) Discuss some standard arguments for the existence of God. (4) Discuss some standard arguments against the existence of God. (5) Conclude with some discussion about the weighing of the arguments presented in the course.

I am tempted to say that no course that conforms to this format should be allowed to proceed. But perhaps that would be to go too far. What is clear is that a course with this structure is highly flawed and very likely to seriously mislead students.

Philosophy of religion should not be about the standard array of 'arguments for and against the existence of God'. Indeed, philosophy of God should not be about the standard array of 'arguments for and against the existence of God'. Insofar as philosophy of religion — or philosophy of God-is concerned with the clash between theistic and atheistic worldviews, the proper way to proceed is: (1) to develop best theistic and atheistic theories; (2) to assess the liability of these best theories to internal defeat; and (3) to make an assessment of the comparative theoretical virtues of these best theories, paying attention to simplicity, fit with data, explanatory scope, predictive accuracy, and the like.

Lest it be thought that this proposal is absurdly radical, it should be noted that much of the content of current courses in philosophy of religion would be preserved in this new setting. The current menu of arguments that is discussed is connected to the data - or putative datathat would properly be discussed in the comparison between theistic and atheistic worldviews: there being something rather than nothing; there being a universe; there being natural laws; there being cosmic fine-tuning; there being eyes and brains; there being rational, conscious agents; there being moral laws; there being dictates of conscience; there being certain religious texts; there being certain religious traditions; there being certain kinds of religious experience; there being certain kinds of miraculous events; and so forth.

However, if our interest is in the question whether God exists, then we should talk directly about whether there is reason to prefer the hypothesis that God exists to the hypothesis that God does not exist, rather than directly about whether there are successful arguments for the 
claim that God exists or for the claim that God does not exist. True enough - as I just notedwhen we talk directly about the standard array of 'arguments for and against the existence of God' we will end up talking about many things that do bear on the question whether God exists. But we also end up talking about all kinds of things that are irrelevant to the question whether God exists, e.g. about whether or not certain kinds of arguments are questionbegging.

6

There may be more general conclusions that we can draw from our discussion. The claim that God exists is only one among many hotly contested, perennially disputed philosophical claims. I am inclined to think that, wherever we have hotly contested, perennially disputed philosophical claims, there is little mileage to be gained from derivations which have those claims as their conclusions.

Consider the claim that we have libertarian freedom. How should we examine this claim? We should construct best theories that embed the claim and best theories that embed its denial; we should work out these theories to the same level of detail; and we should assess them to the same standards against the same range of data. First, we should consider whether these best theories can be defeated on internal grounds; and, second, we should make a comparative assessment of the theoretical virtues of our best theories on a proper weighting of simplicity, fit with data, explanatory scope, predictive accuracy, and so forth.

I don't say that it inconceivable that best theories that claim that we have libertarian freedom - or, alternatively, that best theories that claim that we do not have libertarian freedom - are all subject to reductio. However, I do say that there are no extant derivations that provide reductios of best theories of either kind. Moreover, I think that extant derivations of the claim that we have libertarian freedom, and extant derivations of the claim that we do not have libertarian freedom - suffer from exactly the same kinds of liabilities that characterise extant derivations of the claim that God exists and extant derivations of the claim that God does not exist.

However, if I am right that wherever we have hotly contested, perennially disputed philosophical claims, there is little mileage to be gained from derivations which have those claims as their conclusions, then there may be some broader lessons for philosophical pedagogy.

First - though I admit to being rather unsure about this - I think that there might be a lesson for those who teach introductory logic or introductory critical thinking. In these kinds of courses, we typically introduce students to the distinction between validity and soundness, and we may (unintentionally) convey to students that what is really important about arguments is that they should be sound. But when we are producing reductio arguments, we don't care at all about whether our arguments are sound: all that matters to us is that they are valid. (More generally: when we are producing what I have been calling reductio arguments, we don't care at all about the standing of the premises: all that matters is that the object of our argument believes all of our premises, that our premises really do support our conclusion, and 
that the object of our argument denies that conclusion.) Given that many students take no more than introductory logic or introductory critical thinking, it is very important that those students come away from those courses understanding that there are arguments whose success turns not at all on the standing of their premises.

Second - with similar kinds of reservations - I think that there may be a lesson for those who claim that philosophy is all about argument.

Some people claim that, in order to have a justified belief on a controversial philosophical question, you need to have an argument: that is, you need to have a derivation of your controversial philosophical opinion from other (perhaps less controversial) claims that you accept. It should be obvious by now why I am inclined to suspect that this kind of claim is seriously mistaken. In order to have a justified belief on a controversial philosophical opinion, you ought to have developed a best theory that embeds the belief in question, and you ought to have satisfied yourself that that best theory is not trumped by an extant best theory that embeds the denial of that controversial philosophical belief. But you simply do not need derivations with the controversial philosophical claim as conclusion in order to do these things.

Some people claim that, in order to work out what to think about a controversial philosophical question, you should tally up - or weigh - the arguments on both sides. Again, it should now be obvious why I am inclined to think that this kind of claim is also seriously confused. It is actually best theories embodying the controversial philosophical claim and its denial that should be weighed against one another; and, again, you simply do not need derivations with the controversial philosophical claim and its denial as conclusions in order to do these things.

\section{7}

I am also tempted to draw some lessons that apply to things that philosophers - and nonphilosophers - do outside of the academy. In particular, I think that there are lessons here for public debate about hotly contested, perennially disputed philosophical claims.

Public debate about the existence of God very often presents as a clash between two stockpiles of arguments with the conclusion that God exists or the conclusion that God does not exist. Theists have ontological arguments, cosmological arguments, teleological arguments, moral arguments, arguments from rationality and consciousness, arguments from scripture, Pascal's wager, and so forth; atheists have arguments from evil, arguments from hiddenness, arguments from non-belief, arguments from the conflict between science and religion, arguments from the incompatibility of divine attributes, and so on. Victory in this public debate goes to the side that has the better arguments with either the conclusion that God exists or the conclusion that God does not exist, or the side that is favoured by the weight of arguments with either the conclusion that God exists or the conclusion that God does not exist, or perhaps even just to the side that presents the most arguments with either the conclusion that God exists or the conclusion that God does not exist. 
I think that philosophers ought to be working to change the terms in which public debate about the existence of God - or, indeed, public debate about any other hotly contested, perennially dispute philosophical claim-is understood.

Given a clash between two worldviews, the basic question to be addressed is whether there is reason to prefer one worldview to the other. To answer that question, the most important preliminary tasks are (a) to arrive at best formulations of both worldviews; and (b) to understand how the comparative virtues of worldviews are to be assessed. While it is obvious that there can be no serious assessment of two worldviews that does not begin with careful formulation of best versions of both worldviews - and while it is no less obvious that there can be no serious assessment of two worldviews that is not preceded by careful consideration of the criteria by which the merits of worldviews are to be assessed - the 'stockpile of arguments' conception of debate nurtures a climate in which these essential preliminary steps are simply ignored. Moreover - as I have argued in the earlier parts of this paper-when we make a careful consideration of the criteria by which the merits of worldviews are to be assessed and then go on to consider how best versions of worldviews might be weighed according to those criteria, it becomes clear that the only role that might be played by arguments with either the conclusion that God exists or the conclusion that God does not exist is in providing reductios of the opposing worldview. But, for all extant arguments on either side in these public debates, it is obvious that those arguments do not provide reductios of the opposing worldview; and, in most cases, it is obvious that those arguments do not even purport to be reductios of the opposing worldview.

\section{8}

On the assumption that there are best theories embedding CLAIM and CLAIM that are not subject to reductio - described in Section 1 above - we might reimagine the dispute between PRO and CON about CLAIM as a dispute between embodiments of best global theories embedding CLAIM and CLAIM, $\mathrm{T}_{\text {CLAIM }}$ and $\mathrm{T}_{\sim \text { CLAIM }}$. If we think about the dispute in these terms, then it is obvious that there are infinitely many derivations of CLAIM from sets of claims that belong to $\mathrm{T}_{\mathrm{CLAIM}}$, and that there are infinitely many derivations of $\sim$ CLAIM from sets of claims that belong to $\mathrm{T}_{\sim \text { CLAIM. }}$. Moreover, it is also obvious that there are infinitely many highly complex derivations of CLAIM from large sets of claims that belong to $\mathrm{T}_{\text {CLAIM }}$, and that there are infinitely many highly complex derivations of CLAIM from large sets of claims that belong to T $\sim$ CLAIM.

These observations seem to me to add more weight to the claim that the sole genuine role that derivation - with central, hotly contested, perennially disputed philosophical claim as conclusion - can play in decision between worldviews is in providing reductios of worldviews that are susceptible to reductio. If worldviews are not susceptible to reductio, then there is nothing left for derivation - with central, hotly contested, perennially disputed philosophical claim as conclusion - to do. In particular, as we have just noted, there is nothing to be gained by the exhibition of derivations of CLAIM from sets of claims that belong to $\mathrm{T}_{\text {CLAIM }}$ - or by the exhibition of derivations of $\sim$ CLAIM from sets of claims that 
belong to $\mathrm{T}_{\sim \mathrm{CLAIM}}$ - since we know a priori that there are infinitely many such derivations on each side.

These observations also fill out some claims that I made in Section 3. Since there are infinitely many derivations on each side, exhibiting some of these derivations cannot increase the credence of one side relative to the other. Since there are infinitely many derivations on each side, exhibiting some of them cannot increase the resilience, and reduce the liability of defeat, of one side relative to the other. Since there are infinitely many derivations on each side, exhibiting some of them cannot show that one side is more coherent than the other. Since there are infinitely many derivations in each side, exhibiting some of them cannot establish that one side is a more reliable base than the other for launching arguments against the opposing side.

\section{9}

Although it is somewhat tangential to the main aims of this paper, it is perhaps worth noting that there are reasons for doubting that worldviews that embed hotly contested, perennially disputed philosophical claims are vulnerable to reductio by the putative reductios that are currently available, or even by the kinds of putative reductios that are currently available.

Sure, it sometimes happens that a best theory involving a hotly contested, perennially disputed philosophical claim is defeated by reductio: but, in those cases, there are almost always other best theories that are available to those inclined to accept the claim in question.

Moreover, the very fact that we are dealing with hotly contested, perennially disputed philosophical claim suggests that there is no extant straightforward reductio of theories on either side of the dispute: for, if such reductios were extant, then it would be inexplicable why dispute about the claim persists among philosophers. And, furthermore, this same fact suggests that there are no easy reductios of theories on either side of these disputes that await discovery: for, given the amount of effort that philosophers have invested in looking for such reductios, it would be very surprising if there were easy ones that still await discovery.

Of course, these are not reasons for supposing that it is a complete waste of time to go on looking for reductios in connection with hotly contested, perennially disputed philosophical claims: there is nothing in these considerations that rules out the discovery of reductios of theism or reductios of naturalism. But these are plausibly reasons for supposing that we should invest much more of our effort in weighing the theoretical virtues of theism and naturalism, at least once we have sufficiently well-developed versions of theism and naturalism.

Furthermore, if my remarks in sections 4-6 are well-taken, then these considerations also suggest that public debate, philosophical pedagogy, and the philosophical research literature should also give a much greater amount of attention to attempts to weight the theoretical virtues of theism and naturalism, and much lesser attention to attempts to generate reductios of either view. In particular, if it is obvious that a purported reductio requires premises that do not belong to the worldview to which the purported reductio is supposed to apply, then it 
should be recognised on all sides - in public debate, or in the philosophy classroom, or in the philosophical literature - that there is no need for any further discussion of that purported reductio.

10

As I said at the beginning, I do not think that philosophy of religion should be conflated with philosophy of theism, or philosophy of Christianity, or philosophy of some particular denomination of Christianity. However, even if you wish to pursue philosophy of theism, or philosophy of Christianity, or philosophy of some particular denomination of Christian, you should not make the mistake of supposing that derivations with the conclusion that God exists or the conclusion that God does not exist are central to that pursuit, except insofar as you think that there derivations really are interesting purported reductios of the claim that God exists or the claim that God does not exist. 